\title{
Research on cost management of wenzhou huafeng group co., LTD. Under the background of big data
}

\author{
Wang Yang \\ Dalian university of science and technology, College of Economic and Managementline, dalian, liaoning
}

\begin{abstract}
With the convergence of information technology and human production and life, as well as the rapid popularization of the Internet, the global data show an explosive growth. Accounting, especially cost management, is also closely related to external data. Therefore, the cost management also needs to apply the big data technology to realize its function and method synchronization optimization. This paper first USES the literature research method to sort out the relevant concepts and theories of enterprise cost management at home and abroad, then USES the data analysis method to analyze the current situation and main problems of wenzhou huafeng group co., ltd. in the cost management, and finally, combined with the background of big data, puts forward the corresponding countermeasures through the problems. In a word, through research and analysis, the problems and deficiencies in cost management of enterprises are found, and on the premise of the background of big data, Suggestions and countermeasures are put forward to solve the problems in cost management of enterprises.
\end{abstract}

\section{Introduction}

With the rapid development of the Internet, the concept of big data arises at the historic moment and becomes another technological change after the Internet of things. With the advent of the era of big data, enterprises' business activities cannot be separated from the external environment, and their internal management work also needs to be coordinated with the external information of enterprises. Through the study of enterprise cost management knowledge and practice to discuss the cost problems existing in the enterprise development process, then to the current technology of big data as a basis and thinking on the inquiry, analysis the role of use big data to optimize the cost management, puts forward some concrete first slightly to optimize enterprise cost management defect, finally through a concrete analysis, actual enterprise realize the theory and application, truly optimize the enterprise cost management, it is also under the background of rapidly developing age of big data, large data forward needs together with the cost management theory to practice.

\section{Cost status of wenzhou huafeng group co. LTD}

\subsection{Wenzhou huafeng group basic information}

Wenzhou huafeng group was founded in May 1991. It is a large private joint-stock enterprise with new materials as its main business and real estate, logistics, finance and other industries as its auxiliary. At present, the company has more than 3200 employees and total assets of more than 6 billion yuan. In 2009, the manufacturing industry realized sales revenue of 5.683 billion yuan and profits and taxes of 798 million yuan. In terms of comprehensive strength, it has been listed in the "top 500 competitive power of China's large enterprise groups", "top 500 manufacturing enterprises", "top 500 private enterprises" and "top 100 petroleum and chemical industries" for many years. Over the past 19 years, through continuous development and innovation, huafeng has crossed a new level one after another and created many firsts in the industry in China. Huafeng has become one of the largest manufacturer of polyurethane shoe resin and largest, the world's third largest spandex fiber production enterprises, the company mainly research and development production of polyurethane resin concentrate (sole, leather) with resin, polyurethane elastic fiber (spandex), microfiber synthetic leather and heat preservation materials, aluminum foil, etc. Series of products, polyurethane resin, polyurethane two major series of products by the national famous brand advancement committee awarded the "China famous brand products". The sales income of wenzhou huafeng group co., ltd. in recent years is shown in table 1.

TABLE I. WENZHOU HUAFENG GROUP THREE YEARS OF SALES REVENUE

\begin{tabular}{|l|l|l|l|}
\hline Time & 2017 & 2018 & 2019 \\
\hline Sales revenue & 284422.84 & 414968.42 & 443571.3 \\
\hline
\end{tabular}




\begin{tabular}{|c|l|l|c|}
\hline Time & 2017 & 2018 & 2019 \\
\hline $\begin{array}{c}\text { (ten thousand } \\
\text { yuan) }\end{array}$ & & & 9 \\
\hline
\end{tabular}

According to table 1, we can clearly see that the sales revenue of wenzhou huafeng group is increasing year by year, and in 2019 , it has reached 4435713,900 yuan.

\subsection{Cost status of wenzhou huafeng group co. LTD}

\subsubsection{Purchase cost status}

Wenzhou huafeng group is a manufacturing enterprise, and the procurement process is very important to the cost management of the enterprise. The procurement costs of wenzhou huafeng group are shown in table 2 below.

TABLE II. WENZHOU HUAFENG GROUP PROCUREMENT COST TABLE

\begin{tabular}{|c|c|c|c|}
\hline Time & 2017 & $\mathbf{2 0 1 8}$ & $\mathbf{2 0 1 9}$ \\
\hline $\begin{array}{c}\text { procurement } \\
\text { cost }\end{array}$ & 26252.23 & 45624.00 & 58325.12 \\
\hline $\begin{array}{c}\text { operating } \\
\text { receipt }\end{array}$ & 284422.84 & $\begin{array}{c}414968.4 \\
2\end{array}$ & $\begin{array}{c}443571.3 \\
9\end{array}$ \\
\hline proportion & $9.23 \%$ & $11.00 \%$ & $13.14 \%$ \\
\hline
\end{tabular}

Through the analysis we can get the table 2, wenzhou huafeng group in 2017-2019, the purchasing cost is not low, 262.5223 million yuan, 456.24 million yuan and 583.2512 million yuan respectively, business income accounted for $9.23 \%, 11.00 \%, 13.14 \%$, the purchasing cost and accounted for the past three years has been rise, and in terms of revenue share, compared to 2018 increased by $1.77 \%$ in 2017, and compared to 2019 increased by $2.14 \%$ in 2018 , increase rate increased year by year.

\subsubsection{Production cost status}

TABLE III. WENZHOU HUAFENG GROUP PRODUCTION COST TABLE

\begin{tabular}{|c|l|l|l|}
\hline Time & 2017 & 2018 & 2019 \\
\hline $\begin{array}{c}\text { cost of } \\
\text { production }\end{array}$ & 65329.02 & 74993.21 & 90698.56 \\
\hline $\begin{array}{c}\text { year-on-year } \\
\text { growth }\end{array}$ & $14.80 \%$ & $20.94 \%$ \\
\hline
\end{tabular}

We can see from table 3, wenzhou huafeng group's production costs are rising in recent years, 2017-2019, the production cost is 653.2902 million yuan and 749.9321 million yuan respectively, 906.9856 million yuan, which, in 2018 than in 2017, up $14.80 \%$ from a year earlier, in 2019 than in 2018, up 20.94\% from a year earlier, in 2018 year-on-year growth rate compared with the year-on-year growth rate in 2018 was $6.14 \%$ higher, further speed up year-on-year growth.

\subsubsection{Status of sales expenses}

TABLE IV. WENZHOU HUAFENG GROUP PRODUCTION COST TABLE

\begin{tabular}{|c|l|l|l|}
\hline Time & 2017 & $\mathbf{2 0 1 8}$ & $\mathbf{2 0 1 9}$ \\
\hline $\begin{array}{c}\text { selling } \\
\text { expenses }\end{array}$ & 8860.89 & 13752.99 & 21303.38 \\
\hline $\begin{array}{c}\text { year-on-year } \\
\text { growth }\end{array}$ & $54.55 \%$ & $55.21 \%$ & $54.90 \%$ \\
\hline
\end{tabular}

From table 4, we can see that the enterprise has indeed invested a large amount of funds in sales in recent years. From 2017 to 2019, the sales expenses of the enterprise are 88,608,900 yuan, 137,529,900 yuan and 213,033,800 yuan respectively. Compared with the previous year, the annual change range is more than half, with year-on-year growth of $54.55 \%, 55.21 \%$ and $54.90 \%$ respectively.

\subsubsection{Management expenses and current salary payable to employees}

To a certain extent, the management of costs is influenced by the administrative expenses and the salary payable to the employees. In recent three years, the proportion of the management expenses and the salary payable to the employees in the total cost of wenzhou huafeng group and the proportion of the whole industry in the administrative expenses and the salary payable to the employees are respectively accounted for, as shown in table 5 below.

TABLE V. WENZHOU HUAFENG GROUP MANAGEMENT EXPENSES AND PAYABLE STAFF COMPENSATION PROPORTION TABLE

\begin{tabular}{|c|c|c|c|}
\hline Time & 2017 & 2018 & $\mathbf{2 0 1 9}$ \\
\hline $\begin{array}{c}\text { The total } \\
\text { cost }\end{array}$ & 220998.45 & 376799.63 & 414589.56 \\
\hline $\begin{array}{c}\text { Management } \\
\text { fees }\end{array}$ & $21,139.08$ & $26,333.27$ & 35043.56 \\
\hline $\begin{array}{c}\text { Percentage } \\
\text { of total cost }\end{array}$ & $9.6 \%$ & $7.0 \%$ & $8.5 \%$ \\
\hline $\begin{array}{c}\text { Industry } \\
\text { accounted } \\
\text { for }\end{array}$ & $8.0 \%$ & $5.9 \%$ & $7.8 \%$ \\
\hline $\begin{array}{c}\text { Salary } \\
\text { payable }\end{array}$ & $5,694.05$ & $6,830.92$ & 7893.65 \\
\hline $\begin{array}{c}\text { Percentage } \\
\text { of total cost }\end{array}$ & $2.6 \%$ & $1.8 \%$ & $1.9 \%$ \\
\hline $\begin{array}{c}\text { Industry } \\
\text { accounted } \\
\text { for }\end{array}$ & $2.4 \%$ & $1.65 \%$ & $1.72 \%$ \\
\hline
\end{tabular}

We can see from the table 5, wenzhou huafeng group management costs rise year by year, from 2017 to 2019 , the proportion of total costs were $9.6 \%, 7.0 \%, 8.5 \%$, were higher than the industry accounts for $8.0 \%$ of the proportion of the total cost management cost, 5.9\%, $7.8 \%$, respectively, $1.6 \%, 1.1 \%, 1.7 \%$, higher than that of three years showed a trend of rise after falling first, but is still higher than the industry as a whole accounted 
for than every year, of which 2019 higher than the industry as a whole accounted for than most. The proportion of payable employee compensation in the total cost increased from $2.6 \%$ in 2017 to $1.8 \%$ in 2018 to $1.9 \%$ in 2019 , which was higher than $2.4 \%, 1.65 \%$ and $1.72 \%$ of the total cost in the whole industry. The change trend was the same as that of administrative expenses, and the proportion was higher than that of the whole industry. From this, we can see that the management expenses and the proportion of the total cost of the compensation of employees in wenzhou huafeng group are higher than that of the whole industry in the past three years.

\section{Wenzhou huafeng group co. LTD. Cost management problems}

\subsection{A lack of planning for purchasing led to a rise in inventories}

The inventory of wenzhou huafeng group co., ltd. increased from RMB 550.127,700 yuan in 2017 to RMB $615.278,900$ yuan in 2018 , and in 2019 , the inventory of the enterprise increased to RMB 717.755,100 yuan. The inventory cost of the enterprise showed a continuous rising trend, and the year-on-year growth rate gradually accelerated. In the current economic environment of China, in order to meet the needs of the development of the era of big data, most manufacturing enterprises in China have gradually implemented budget control and cost planning through the use of big data to manage the costs of enterprises. Cost plan has a pivotal position in the cost management, cost plan can accurately predict the cost, make the goal of enterprise cost management, then according to the comprehensive control of target to each link, so is the foundation of the link of cost plan, ensure the whole cost management plan can smoothly, only scientific and reasonable plan can ensure the effect of the whole cost management significantly, provide help to improve the economic benefits of the enterprises. But in the actual operation process, wenzhou huafeng group showed in the link of cost plan is not value, a lot of cost plan link formalization is very serious, in a form of manner, thus make the enterprise in the purchase was not to purchase according to the actual demand, caused the procurement costs continue to rise for years, but it did not translate into revenue, caused the stock rise, make the cost increase, not by actively comply with the development trend of today's data, there is no use big data to construct a complete system of cost budget and cost plan, makes the following link to rigorous smoothly completed, The situation of cost budget and data lost the reference, so in the next link can only be difficult to move forward, and the speed is relatively slow, so the cost management work lacks its substantive role. At the same time, because the wenzhou huafeng group co., LTD. Ignore the management of the budget control and cost plan, thus in daily business without cost plan and budget control, makes the enterprise did not establish a perfect comprehensive budget system, calculation, more do not advance matter controls, afterwards, rewards and punishments, makes the product production is greater than the pin and massive stockpiles, thereby causing the inventory cost of the enterprise for years to continue to rise, thereby increasing the overall costs rise, in the process of enterprise in the business caused pressure in cost management of the enterprise.

\subsection{Excessive division of production leads to increased costs}

Wenzhou huafeng group co., LTD is a large enterprise, many internal production personnel in the workshop, the production cost is made up of direct materials, direct labor, manufacturing costs, the direct material proportion in enterprises declined year by year, but the direct labor and manufacturing cost of rising year by year, further investigate its reason, the enterprise in the cost of production in the process of production, wenzhou huafeng group failed to combine these days the background of big data, personnel division of labor is too thin, could have been done by a person of production is divided into the by more than one person to complete, waste of labor and manufacturing resources, enterprise internal production division of labor is more and more fine, The enterprise internal must carry on the high degree cooperation management, thus causes the enterprise to coordinate the labor cost in the production process to be too high. Enterprises in the production process, on the other hand, the division of labor, the production cost of the enterprise management gradually complicated situation development, hinder the promotion enterprise's production cost efficiency, for enterprise to bring a certain efficiency with low production cost, so enterprise on the aspects such as economy, human resources, there are serious waste phenomenon, become one of the reasons for the enterprise production cost increase. Because companies ignore the application of large data, the data collection, integration and analysis capabilities not reflected in the cost of production management, the division level and the increase of the collaborative links, at the same time, the company failed to use big data to timely update the information, in the process of production has failed to live up to the elaborating management, lead to enterprise lags behind in terms of access to information, lead to in the enterprise information transfer time extended, the production of the enterprise personnel failed to get the customer for the product related requirements, leading to the production of products is not recognized by enterprise customers and increase the rate of the defective products, so as to make the enterprise production in the process of manufacturing cost.

\subsection{The cost of sales increased too quickly}

TABLE VI. WENZHOU HUAFENG GROUP ADVERTISING FEE AND PROPORTION TABLE

\begin{tabular}{|c|c|c|l|}
\hline Time & $\mathbf{2 0 1 7}$ & $\mathbf{2 0 1 8}$ & $\mathbf{2 0 1 9}$ \\
\hline advertising & 4377.23 & 7098.68 & 13526.09 \\
\hline Cost of sales & 8860.89 & 13752.99 & 21303.38 \\
\hline $\begin{array}{c}\text { The } \\
\text { proportion }\end{array}$ & $49.40 \%$ & $51.62 \%$ & $63.49 \%$ \\
\hline
\end{tabular}


We can see from the table 6 , cost of sales is increased year by year in wenzhou huafeng group, in-depth analysis, it is mainly because enterprises caused by the increase in advertising investment, advertising accounts for the proportion of the cost of sales increased gradually, nearly four years are close to half, by the year 2019 is accounted for more than sixty percent of the cost of sales, as a result, the rise in the cost of advertising to a large extent affected the cost of sales, make its substantial increase, but enterprise's sales revenue growth is slow, make substantial advertising investment and operating income does not match. Nowadays, big data has grown, through large data led to the development of related to the development of the Internet industry, wenzhou huafeng group while in advertising for a large amount of investment, but the way more traditional, or through the traditional way of advertising and marketing the sale of the products, but this $\mathrm{AD}$ called for popular with older consumers, now society, youth and middle-aged gradually become the main body of consumption, their thoughts and consumption pattern, more innovative mobile phone has become now consumption main body essential important means of communication and information advertising, And wenzhou huafeng group without using big data in the process of product sales to now the information such as the consumption main body of the thought and way for integration and analysis, can't timely and desire for consumption subject with its consumption psychology of advertising content, not using big data in a timely manner with the combination of the Internet, via the Internet, the potential consumption subject to send mobile ads, etc., cause consumers fail to know the products of the company, and the characteristics of the product, the consumer recognition of enterprise product is low, and the enterprise is in vain spent a lot of advertising and not bring the original sales revenue.

\subsection{The imperfect supervision system leads to the increase of wages and administrative expenses}

Wenzhou huafeng group co., LTD. Management cost is ten thousand yuan in 21139, in 2017 and 2018, rising to 26333.27 ten thousand yuan, in 2019 rose to 350.4356 million yuan, deal with employee compensation, up from ten thousand yuan in 2017 to 5694.056830 .92 ten thousand yuan in 2018, to 2019 rose to 78.9365 million yuan, the management cost and deal with worker firewood in three years continue to rise, and rise rapidly, this suggests that enterprise personnel management is loose, not to establish a perfect supervision system, In wenzhou huafeng group part of the personnel's income and to create value for the enterprise does not correspond, inside the company failed to use big data to form a set of strict supervision system, lead to internal regulation by artificial regulation, there are many human relations of a series of problems, staff awareness of cost management, staff basic literacy, company management personnel to the degree of cost control, company group personnel acceptance for cost management, different job requirements between staff and the relationship between the staff and leadership at the grass-roots level is more involved. Another aspect, wenzhou huafeng group due to the recent years will focus on the development of the enterprise, excessive emphasis on enterprise economic development while ignoring the use big data to perfect the supervision system, make the pace of the supervision system can't keep up with the rapid development of the enterprise, each department is only in their own responsible for regulated within the scope of business, the overall supervision and form a diversified, bulk state, difficult to form combined force of supervision.

Aiming at this situation, the wenzhou huafeng group co., LTD. Does not take positive and effective measures to perfect the supervision system of cost management, for the enterprise internal employee lack of regulation in the business and financial processes, but continue to develop the business, the pursuit of enterprise's operating profit, the company's senior management personnel due to the need of the development of the enterprise and macro regulation, even saw the enterprise current regulatory problems, also because there is no extra energy and think the management fees and cope with the increase of worker pay compared with the economic development of the enterprise isn't worth mentioning, ignore the regulation, This makes the company's accounting personnel because of no corresponding regulation on the handling of finance, new business is very casual, to a certain extent, also increased the enterprise cost in the intangible losses, but the lack of regulation in the long term, will cause the enterprise personnel a laid-back, casual attitude, make the enterprise management fees and cope with further increases in employee compensation in imperceptible in, can give a company in terms of cost management has caused a certain pressure, make enterprise's policymakers due to cost increase for the future decisionmaking hesitant,, in turn, affect the development of the enterprise in the future, affect the enterprise profitability and development prospects. While at the same time, wenzhou huafeng group made the cost management supervision system, but there are certain subjectivity due to human oversight, the lack of big data is used to establish the corresponding system as the objective, the strict supervision system, the related personnel is not in strict accordance with the requirements of the system to supervise, this is planted hidden danger for the development of enterprise, affect the future of his position in the industry make it lost its advantage in terms of competitiveness.

\section{Enterprise cost management optimization strategy under the background of big data}

\subsection{Enhanced procurement planning}

Aiming at the existence of wenzhou huafeng group purchasing a lack of planning, the problem of large inventory, enterprises should strictly before purchasing planning, use of big data to analyze the demand of the enterprises in the procurement, with the development of times, actively use big data to construct the purchasing budget control and purchasing cost control platform, provide a reference for enterprises in the aspect of understanding the market demand, to avoid enterprises 
due to don't understand the market demand and purchasing of material waste and excess inventory. In terms of strengthening budgetary control:

First, to fully and comprehensively to ensure the implementation of the budget, big data was used to construct the "from top to bottom, from bottom to top", such enterprises can be ensured the following departments fully understand the overall goal of enterprise, also can ensure the above leadership timely learned the truth of the following departments, this is because in the actual operation process, the cost budget is not solely through "on the" simple and easy way can finish, but through the "two up two down" type of repair is good, for wenzhou huafeng group is a manufacturing enterprise, according to the business situation and adjust your own situation, It is necessary to make quarterly, semi-annual and annual budgets by using big data.

Second, the rigid implementation of cost budget is inseparable from the construction of big data procurement platform. To enable employees to understand the big data procurement platform, understand the budget system and preparation under the big data procurement platform, understand the budget target, know what can be done and what cannot be done in order to achieve this goal, and prevent the budget overruns caused by arbitrary changes and flexibility of employees in the process of budget implementation; On the other hand, the enterprise as a whole should attach great importance to the importance of budget management, strictly abide by the budget management system and perform the budget examination and approval procedures, and not arbitrarily increase or reduce the expenditure items unrelated to the budget, so as to ensure the smooth implementation of the entire budget management. To solve this problem of cost planning, I put forward three Suggestions: first, through the analysis of the big data cost planning platform, we can effectively grasp and predict the price trend of materials. In today's era of big data, cloud computing technology is no longer a problem for enterprises. By integrating the funds needed to purchase materials before, we can predict the price trend of materials. The second is to achieve fine management of orders and production. In the case of meeting the production needs, the inventory can be reduced to a safe value based on the big data platform, so as to timely avoid the huge backlog of funds in materials, which leads to the difficulty of capital turnover. Third, the use of big data to fully understand the market. Enterprise should use big data collecting relevant data and process integration, the market demand to understand the demand of the market, thus targeted production products, have reached the maximization of product sales, to avoid the products can't meet the requirement of market and consumers and cause the increase of inventory, makes the rising costs of enterprises.

\subsection{Integrate production process to reduce unnecessary production division}

Wenzhou huafeng group to the personnel division of a serious study of enterprises nowadays, on the basis of combining large data for production to carry on the careful analysis, determine the enterprise in the production of the core tasks, withdraw some irrelevant to this link, reduce unnecessary production division of labor, to avoid some unnecessary waste of the cost of production. The era of "big data" brings rapid development to enterprises, and also brings a new look to the cost management of enterprises. The high efficiency of big data has gradually replaced the low efficiency mode of traditional financial management, which provides more valuable data for the decisionmaking level of enterprises, and also enables enterprises to realize fine management in production. Therefore, enterprises should actively use big data technology to realize the comprehensive electronization of the production link of enterprises, establish a daily production capacity of production staff through the analysis of big data, and clean up the excess production staff of enterprises, so as to avoid the waste increase of direct labor costs without producing products of corresponding value. At the same time, the process can be coordinated by big data to establish a unified information platform, let all business processes and coordination is realized in big data platform to integrate and coordinate with informatization platform support to resolve all by artificial coordination to achieve process coordination of idea, in the process itself of all kinds of system and process, through the function, permissions, and workflow Settings for curing, effectively improve the efficiency and accuracy of management system integration, effectively reduce the tire which made by the personnel coordination and the associated costs.In addition, the information technology can also make the relevant personnel in the design of the production and change is more convenient and efficient manner. In the construction of information channel, the enterprise to take advantage of big data design and construction scientifically, make information in a timely manner to the necessary link, reduce unnecessary stagnation, guarantee the cost information unblocked, real and effective, with big data can be collected related enterprise customer related feedback information for enterprise products, enterprises will these information through a multi-angle and multi-level large data mining and analysis, found problems in the process of production in time and in a timely manner to meet customer demand for products and to reduce the defect rates of the products, To promote the production activities of enterprises to take the road of data and rationalization, optimize the business process of enterprises to the greatest extent, restrain some unnecessary waste and cost loss of enterprises in production, realize the maximization of economic benefits, and promote the better development of enterprises in the future.

\subsection{Use big data to control sales expenses}

Under the background of the era of big data, the enterprise product sales mode has entered a new development mode, but wenzhou huafeng group still adopts the traditional advertising mode in product sales, which is obviously not in line with the requirements of the development of The Times, as a result, the enterprise has invested a lot of advertising fees without receiving the corresponding return. To solve this problem, 
wenzhou huafeng group should actively conform to the development of The Times, apply the big data technology to the sales of enterprises, and obtain the advertising contents and forms of current consumers' interest through the integration of information and analysis of information functions of big data. Enterprises can make electronic posters and posters by big data, and through the now popular WeChat, weibo etc advanced network communication way to send the product information, introduces the function and characteristics of products, supply the way for the enterprise product sales channels, and to save advertising costs of the enterprise. At the same time, the enterprise can be obtained by big data to accurately understand and consumer demand for products, put the product in the market for the enterprise provides the reference, effectively prevent the enterprise sales revenue into advertising but did not receive due the advertising expenses caused by waste, increased the cost of sales, resulting in the increase of the whole enterprise cost, allows businesses to put pressure on the cost management, restraining to the enterprise's future development.

\subsection{We will improve the supervision system}

For wenzhou huafeng group in supervision system is not complete, the enterprise internal staff work attitude is relatively loose and cause enterprise management cost and deal with worker firewood high question, wenzhou huafeng group as a whole should attach great importance to the perfection of the supervision system, in the current economic environment of overall national development is rapid, virtually every industry increasingly fierce competition, every enterprise is faced with many opportunities and challenges, therefore, to respond to the call of The Times, actively use big data to optimize the supervision system, the supervision system of enterprise is more objective and fair. For the accounting and financial personnel of an enterprise, they are crucial to the development of the enterprise and the supervision of these personnel is indispensable. Therefore, the internal accounting control and audit of the enterprise should be paid more attention to in order to further strengthen the restraint mechanism by using relevant laws and regulations. Enterprises should ensure the scientific rationalization of the supervision system when formulating the supervision system, closely follow the national "accounting law" and other provisions, through the normative role of the system to significantly reduce the accounting information generated by fraud, incomplete, not timely, distortion and other problems, for the market economy supervision and the normal operation of clearing the way. With the rapid development of information technology, the impact of big data and Internet on accounting supervision is increasing. If we want to make accounting supervision work also follow the trend of The Times, we need to pay attention to the following points: first, to achieve the transformation and upgrading of supervision cost management work, enterprises to form an Internet thinking, relying on the characteristics of the Internet economy to innovate the way of cost management supervision. For example, information update information update is one of the characteristics of the Internet, so the cost management should also achieve constant monitoring, timely feedback. Second, enterprises make full use of cloud computing in supervision work. In the era of the rapid development of cloud computing, mobile Internet, big data and other related technologies, the processing of accounting information is more real-time, dynamic and centralized. At the same time, in order to better play the function of accounting supervision and ensure the true, reasonable and legal conduct of enterprise economic activities, cloud computing system can also play the role of strengthening the use of accounting information analysis, to a certain extent, to assist the decision-making behavior of enterprise decision makers. Third, we should make good use of big data thinking to introduce supervision work systematically. On the basis of information system, carry out automatic sampling checking and calculation on various data of economic activities and costs of enterprises, and proofread the data of manual bookkeeping with financial accounting, so as to strengthen supervision on the accounting of enterprises.

\section{References}

1. Feng qiaogen. Cost management and control [M], China renmin university press, 2016.

2. CAI qiaoqiao. Research on innovation performance of China's big data industry [D], Beijing university of posts and telecommunications, 2017

3. Lin rukai. Analysis and exploration of problems related to mechanical and electrical installation cost management of water conservancy projects $[\mathrm{J}]$, pearl river transportation, 2018.

4. yu guozhen. Research on cost control of private manufacturing enterprises [J], national circulation economy, 2018, 2096-3157.

5. tong wei. Problems and optimization strategies in enterprise financial management [J], modern marketing, 2017 (12), 1009-2994.

6. wu yu. Discussion on cost management in passenger vehicle development stage $[\mathrm{J}]$ automotive practical technology, 2018.

7. wang gang. Current situation and problems of construction project cost management [J], building materials and decoration, 2018.

8. sun mei. Audit research on cost management and pre-settlement of housing construction project [J], building materials and decoration, 2018. 